\title{
Effect of Strategic Timelines on the Performance of Technical Training Institutions in Meru County, Kenya
}

\author{
George Mungiria Muthaa \\ Department of Education, \\ Chuka University, Kenya \\ Email: gmuthaa [AT] yahoo.com
}

\begin{abstract}
Organizational performance is important in justifying its existence and resources allocation. To enhance performance Strategic plans have been identified as useful management tools to achieving competitive advantage. Technical Training institutions have been operating with strategic plans for at least the last ten years; however no systematic study has been carried out to investigate the influence of the strategic timelines on the performance of the institutions. The current study sought to investigate the effect of the strategic timelines on performance of Technical Training Institutions in Meru County. The study used cross sectional descriptive survey research design. The survey was conducted with the top, middle and lower level management of the institutions. Questionnaires were used for data collection. Data was analyzed by use of both descriptive and inferential statistics including frequencies, percentages, means, correlations and the regression analyses. The findings were presented in tables and figures. The study established that timelines having a significant influence on performance. The government policy enhanced the effectiveness of the strategic timelines on the performance of technical training institutions. The researcher recommends the alignment of the institutional philosophy, priorities, innovations and collaborations to the institutional strategic plans which could improve the performance of Technical Training Institutions.
\end{abstract}

Keywords- Strategic timelines and Performance

\section{INTRODUCTION}

Organizations are developed with the objective of providing service to society. The organizations compete for resources with other sectors of the economy. The continued funding for such organizations can be justified by their performance. However, the environment is complex, turbulent and dynamic (Johnson et al, 2008). The exigencies in the remote and immediate environment further intensify competition for supplies and markets creating uncertainties that present opportunities, threats and constraints to firms (Barney, 2007). Porter (1985) found that corporate strategy is an essential management tool to achieving a firm's performance through strategic initiatives. It's against this backdrop that the concept of strategic plan has become popular as a management's tool not only to steer a firm's survival but also improve performance.

The desire for Strategic plans in Kenya commenced slowly and gradually back in the 1960s but has presently gaining currency and popularity (Yabs, 2007). The public sector finds the concept of strategic plans just as important as in commercial firms and hence Technical Training Institutions in Meru County are required to formulate strategic plans in tandem with the MoE's strategic plan in order to foster the government's agenda to provide trainees with the quality education and training (Birgen, 2007). Strategic plans are expected to positively influence performance by enhancing the financial and non- financial outcomes in the training institutions. This makes the strategic plans a necessary management tool for Technical Training Institutions in Meru County if these institutions are to justify their public financial support and produce graduates that help in meeting the country's development vision.

A number of scholars such as Cole (2004) and Ansoff (1990) have argued that there is a positive correlation between strategic planning and performance while others argue that the relationship between planning and performance is inconsistent and thus still debatable (Barney 2007, Thompson et al, 2007). There have been studies on influence of strategic planning on performance in other education sectors. For instance, Mukokho (2010) studied the influence of strategic planning on performance of public universities in Kenya, the case of university of Nairobi, Gode (2009) studied influence of strategic planning on the performance of public secondary schools in Kisumu East, Ayieko (2009) studied strategic planning practices and performance of manufacturing firms. The above studies recommended for the development of strategic plans to enhance performance in the studied sectors. A study of strategic planning and performance in public secondary schools in Rarienda District by Okwako (2013) indicated the importance of strategy planning in public secondary schools and therefore suggested a replication of the study in different parts of the county 
and other levels of education. Despite the critical role that the Technical Training Institutions play in human resource training and the concern raised with regards to the quality of graduate, the enrolment levels and resources in these institutions, the sectors seems to have been ignored by researchers which shows a knowledge gap that needs to be addressed. Do strategic timelines in strategic plans influence performance in Technical Training Institutions in Meru County? The objective of this study was to determine the effect of strategic timelines on the performance of technical training institutions in Meru County, Kenya.

\section{METHODOLOGY}

This study employed cross-sectional descriptive survey design. Cross-sectional descriptive survey design was the most appropriate design for this study since the researcher sought to collect data on the existing phenomenon with regard to the variables of the study. Members of the management of the Technical Training Institutions in Meru participated in the study. These included the top management, made up of the Principal, the two deputy Principals, the finance officer and the registrar, the middle level management made up of the heads of departments and the dean of students and the lower level management, made up of the heads of sections. All the 124 members of management participated in the study.

Primary data was collected by use Questionnaires. Structured and unstructured items were included in the questionnaire. The questionnaires were administered to the top management, middle and lower level management. Cronbach's alpha was used to estimate the reliability. A reliability coefficient of at least 0.7 is considered appropriate for social studies (Kathuri \& Pals, 2003). Reliability coefficient of at least 0.7 was considered appropriate; instruments with a reliability coefficient of below 0.7 were revised to enhance the reliability. After the validity and the reliability of the instruments had been assured and the research instruments were personally administered by the researcher.

The data was analysed using both descriptive and inferential statistics in Statistical Package for Social Sciences (SPSS) Version 20.0 software. Descriptive statistics was used to specifically measure central tendency and dispersion was computed to profile the respondents and the variables of the study. Pearson's Product Moment Correlation (r) was derived to show the nature and strength of the relationships. Adjusted $\mathrm{R}^{2}$ was used to measure the amount of variations in the dependent variable of change explained by the independent variable of the strategic plan. Regression analyses were conducted to establish the effect of each independent variable on the dependent variable.

\section{RESULTS AND DISCUSSIONS}

The researcher sought information on the academic qualifications of the respondents. The responses are presented in Figure 1.

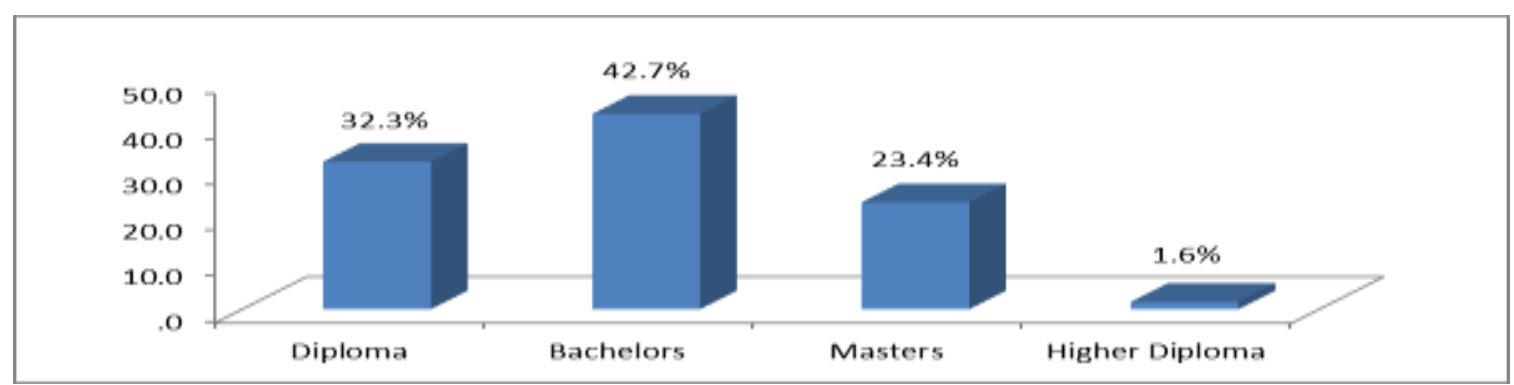

Figure 1. Academic Qualifications of Respondents

Information in Figures 1 shows that $42.7 \%$ of the respondents had a bachelor's qualification while $32.3 \%$ had a diploma qualification.

The researcher sought information on whether the respondents were trained on strategic planning. This information is shown in Figure 2. 


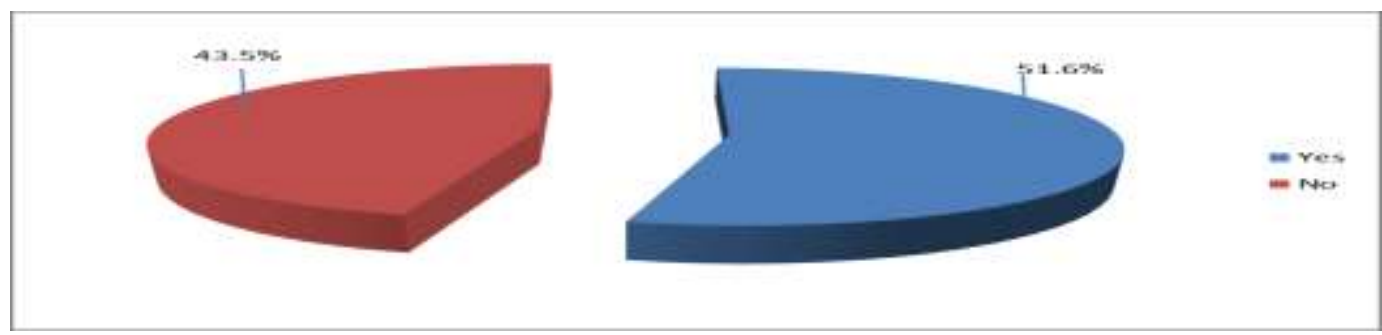

Figure 2. Training on Strategic Planning

Information in Figure 2 shows that majority $(51.6 \%)$ of the respondents had some training in strategic management whereas $43.5 \%$ indicated that they had no training in strategic management. The fraction of $43.5 \%$ of the respondents who have no training in strategic management should be an issue of concern if planning and implementation of the strategic plans has to be effective.

The researcher further sought information from the respondent on their self-rating on competency in strategic planning. This information is shown in Table 1.

Table 1 Competency Level

\begin{tabular}{lcc}
\hline Responses & Frequency & Percent \\
\hline Very competent & 18 & 14.5 \\
Competent & 44 & 35.5 \\
No Opinion & 24 & 19.4 \\
Incompetent & 1 & .8 \\
No response & 37 & 29.8 \\
\hline Total & 124 & 100.0 \\
\hline
\end{tabular}

Information in Table 1 shows that $35.5 \%$ of the respondents rated themselves as competent while $19.4 \%$ of the respondents held no opinion on their levels of competence in strategic planning. Only $14.5 \%$ of the respondents indicated that they were very competent in strategic planning.

The researcher sought information on who developed the institutional strategic plans for the Technical training Institutions. This information is presented in Figure 3.

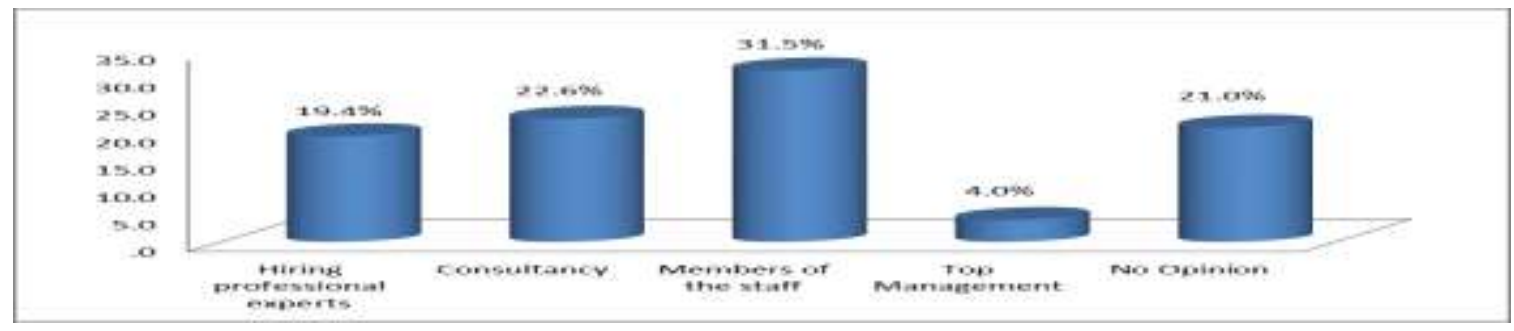

Figure 3. Development of the Strategic Plan

Information in Figure 3 shows that at $31.5 \%$ respondents indicated that strategic plans were developed by the members of staff within the institution whereas $22.6 \%$ indicated that the institution used skilled staff on consultancy bases for the development of the strategic plans. Respondents at $19.4 \%$ indicated that institutions hired professional experts for the development of their strategic plans.

\section{Timeliness}

The objective of this study was to establish the impact of strategic timelines on the performance of technical training institutions. The researcher therefore sought information on the extent to which the dimensions of timeliness are in line with the strategic plan. The findings on this item analyzed by mean and standard deviation are shown in Table 2 . 
Table 2. Timeliness

\begin{tabular}{lccc}
\hline Timeliness & $\mathrm{N}$ & Mean & Std. Deviation \\
\hline Communication of targets & 122 & 3.85 & .942 \\
Implementation of targets & 122 & 3.84 & .837 \\
Effectiveness of services & 122 & 3.89 & .683 \\
Efficiency of services & 120 & 3.88 & .638 \\
innovations & 120 & 3.51 & 1.077 \\
Supervision/support & 122 & 3.88 & .788 \\
Timely results & 122 & 3.90 & .827 \\
\hline Overall mean score & & 3.82 & .827 \\
\hline
\end{tabular}

The results presented in Table 2 shows that on average respondents felt that the dimensions of timeliness were in line with the institutional strategic plan to a great extent. Timely results (mean score $=3.90, \mathrm{SD}=0.827$ ) and the Effectiveness of services (mean score $=3.89, \mathrm{SD}=0.683$ ) were rated most important in the timeliness dimension of the strategic plan. Innovations (mean score $=3.51, \mathrm{SD}=1.077$ ) was rated least on the timeliness dimension of the strategic plan.

\section{Government Policy}

The researcher sought information on the extent to which the Government policy being a moderator variable impacted on the institutions' strategic plan. This information is shown in Table 3.

\section{Table 3 Government Policy}

\begin{tabular}{|l|c|c|c|}
\hline Government Policy & $\mathrm{N}$ & Mean & Std. Deviation \\
\hline Accountability & 122 & 3.98 & .966 \\
\hline stability & 120 & 3.84 & .879 \\
\hline Effectiveness & 120 & 3.82 & .869 \\
\hline Regulatory quality & 122 & 3.97 & .852 \\
\hline Rule of law & 122 & 3.95 & .822 \\
\hline Control of corruption & 122 & 3.90 & .885 \\
\hline Overall mean score & & 3.91 & .879 \\
\hline
\end{tabular}

Information in Table 3 shows that the government policy impacted to a great extent on the strategic plans. Accountability (mean score=3.98, SD=0.966) and Regulatory quality (mean score=3.97, $\mathrm{SD}=0.852$ ) were most important in the institutions strategic plans. Effectiveness (mean score=3.82, $\mathrm{SD}=0.869$ ) and stability (mean score=3.84, $\mathrm{SD}=0.879$ ) were rated least important in the strategic plans.

\section{Performance}

To achieve the objectives of the study, the researcher sought information on the performance of technical training institutions. Various indicators were used to assess the extent of performance by the Technical Training Institutions. This information is shown in Table 4. 
Table 4 Performance

\begin{tabular}{|c|c|c|c|}
\hline & $\mathrm{N}$ & Mean & Std. Deviation \\
\hline Quality & 124 & 4.22 & .657 \\
\hline Quality of trainers & 124 & 3.91 & .884 \\
\hline Quality of infrastructure & 124 & 4.01 & .888 \\
\hline Quality of training tools & 124 & 3.75 & .976 \\
\hline Quality of curriculum & 122 & 3.87 & .970 \\
\hline Quality of skills & 122 & 4.02 & .643 \\
\hline Quality of knowledge & 120 & 3.88 & .881 \\
\hline Quality of graduates & 120 & 3.73 & .995 \\
\hline Resources & 120 & 3.89 & .848 \\
\hline Adequacy of training materials & 120 & 3.61 & 1.079 \\
\hline Infrastructure development & 120 & 3.93 & .909 \\
\hline Human resource development & 120 & 3.79 & 1.003 \\
\hline Availability of teaching materials & 120 & 3.25 & 1.204 \\
\hline Workshop tools \& equipment & 116 & 3.66 & .961 \\
\hline Enrolment & 118 & 3.77 & .861 \\
\hline Students Enrolment & 122 & 3.86 & .816 \\
\hline Retention rates & 122 & 3.78 & .828 \\
\hline Completion rates & 122 & 3.96 & .648 \\
\hline Efficiency & 118 & 4.01 & .722 \\
\hline Efficiency of training process & 120 & 3.78 & .822 \\
\hline Acquisition of practical skills & 122 & 3.80 & 1.018 \\
\hline Utilization of resources & 121 & 3.83 & .886 \\
\hline
\end{tabular}

The results in Table 4 reveals four indicators of performance in technical institutions with a mean of above 4.00. Quality (mean score $=4.22, \mathrm{SD}=0.657$ ), quality of skills (mean score=4.02, SD=0.643), quality of infrastructure (mean score=4.01, $\mathrm{SD}=0.888$ ) and efficiency (mean score=4.01, $\mathrm{SD}=0.722$ ) were rated most important dimensions of performance in the technical training institutions. Availability of teaching materials (mean score $=3.25, \mathrm{SD}=1.204$ ) was rated least among the various indicators of performance in the technical training institutions.

\section{Regression Analysis on Timelines on Performance}

The researcher sought to determine the extent of effect of the timelines to the performance of the institutions. Multiple linear correlation analysis was performed on the extent to which timelines impacted on performance. This information is presented in Table 5.

Table 5 Regression Analysis Results on Timelines and Performance

\begin{tabular}{|c|c|c|c|c|c|}
\hline & \multicolumn{2}{|c|}{ Unstandardized Coefficients } & \multirow{2}{*}{$\begin{array}{l}\text { Standardized Coefficients } \\
\text { Beta }\end{array}$} & \multirow[b]{2}{*}{$\mathrm{t}$} & \multirow[b]{2}{*}{ Sig. } \\
\hline & B & Std. Error & & & \\
\hline (Constant) & 2.764 & .298 & & 9.286 & .000 \\
\hline Timelines & .268 & .077 & .303 & 3.489 & .001 \\
\hline R square $=9.2 \%$ & & & $=12.17(0.001<0.05)$ & & \\
\hline
\end{tabular}

Results in Table 5 show the relationship between timelines and performance. From the model $9.2 \%$ of the variation in performance can be accounted for by the timelines in the model. The F-statistics of 12.17 (p-value $0.0001<0.05$ ) indicates that the overall model was statistically significant at $95 \%$ confidence level. The relationship between timelines 
and performance was statistically significant $(t=3.489, \mathrm{p}$-value $0.001<0.05)$. This implies that for one unit increase in timelines the performance will increase by a factor of 0.268 . The hypothesis that there was no significant relationship between timelines and performance was not supported in the current study. The predictive regression model can be stated as:

$\mathrm{Y}=1.558+0.557 \mathrm{X}_{4}$

Where Y - Performance

$\mathrm{X}_{4}$ - timelines

2.764- Constant

0.268 - Is the estimate of the expected change in performance when role responsibilities is increased by one unit.

\section{Moderating Effect of the Relationship between Timelines and Performance}

The researcher further sought to estimate the relationship between the timelines and performance of the technical training institutions with the introduction of the moderator of the government policy. The findings are presented in Table 6.

Table 6 Regression result of the Timelines with government policy

\begin{tabular}{|c|c|c|c|c|c|c|}
\hline \multicolumn{2}{|c|}{ Model } & \multicolumn{2}{|c|}{ Unstandardized Coefficients } & \multirow{2}{*}{$\begin{array}{l}\text { Standardized } \\
\text { Coefficients } \\
\text { Beta }\end{array}$} & \multirow[t]{2}{*}{$\mathrm{t}$} & \multirow[t]{2}{*}{ Sig. } \\
\hline & & $\mathrm{B}$ & Std. Error & & & \\
\hline \multirow[t]{2}{*}{1} & (Constant) & 2.799 & .300 & & 9.325 & .000 \\
\hline & Timelines & .257 & .078 & .292 & 3.312 & .001 \\
\hline \multirow[t]{3}{*}{2} & (Constant) & 2.205 & .299 & & 7.376 & .000 \\
\hline & Timelines & .033 & .084 & .038 & .396 & .693 \\
\hline & Government Policy & .370 & .075 & .473 & 4.961 & .000 \\
\hline 1 & \multicolumn{6}{|c|}{ R squared $=0.085 \quad$ F-statistic $=10.968(0.000)$} \\
\hline 2 & \multicolumn{6}{|c|}{$\begin{array}{ll}\text { R squared }=0.244 & \text { F-statistic }=18.885(0.000)\end{array}$} \\
\hline
\end{tabular}

Table 6 shows the effects of the moderator variable on the relationship between performance and timelines. It explains $8.5 \%$ of the variation in performance of technical training institutions $\left(r^{2}=0.085\right)$. At step two the government policy adds significantly to the performance as the variation increased from $8.5 \%$ to $24.4 \%$. The results revealed that the variance is explained by the government policy is significance. However in the presence of the moderating variable the relationship between performance and timeline was not statistically significant, hence timeline factor is omitted in the predictive model.

$\mathrm{Y}=2.205+0.370 \mathrm{M}$

Where $\mathrm{Y}=$ performance of technical training institutions

$$
\begin{aligned}
& 2.205=\text { Constant } \\
& \mathrm{M}=\text { Government policy }
\end{aligned}
$$

The implication of the results is that the introduction of the moderator variable makes the timeliness insignificant in influencing the performance of technical training institutions.

\section{CONCLUSIONS}

Judging from the findings resulting from the data collected for this study, the results reveal some vital facts upon which the conclusions are based. One of the things we can deduce from this study is that strategic plans have significant influences organizational performance. 
On the relationship between timelines and performance a unit increases in timelines the performance will increase by a factor of 0.268 . The hypothesis that there was no significant relationship between timelines and performance was not supported in the current study. This shows that strategic timelines have a significant impact on the performance of technical training institutions.

The impact of the moderator variable on the relationship between performance and timelines was sought. The study established that government policy adds significantly to impact of timelines on the performance of technical training institutions. The results revealed that the variance is explained by the government policy is significance. However in the presence of the moderating variable the relationship between performance and timeline was not statistically significant.

\section{RECOMMENDATIONS}

Based on the findings of the current study, the researcher made the following recommendations:

i. There is need for the institutional managers to align the institutional philosophy and the priorities to the institutional strategic plans.

ii. The Staff appraisal and the Developing of employees should be emphasized has important components of the strategic plan which could improve the performance of Technical Training Institutions.

iii. There is need Technical Training Institutions to emphasize on innovations for the timeliness implementation of the strategic plan. The focuses on innovativeness can greatly influence performance in the Technical Training institutions.

\section{REFERENCES}

- Ansoff, I.H. (1990). Implanting Strategic Management. London: Prentice Hall International Ltd.

- Ayieko, M. O. (2011). Strategic planning practices and performance of large manufacturing firms in kisumu,kenya. Master of business administration, school of business, university of Nairobi.

- Barney, J.B. (2007). Gaining and Sustaining Competitive Advantage. 3rd Ed. New Jersey: Pearson Hall.

- Birgen, P. (2007). Strategic Plan: How to develop a strategic Plan. Colour print ltd:Nairobi.

- Cole, G. A. (2004). Management Theory and Practice. 6th Ed. London: Thomson Learning Bedford Row.

- Cronbach, L. J. (1951). Coefficient Alpha and the Internal Structure of Tests. Psychometrika, 16 (3): $297-334$.

- Gode, H. (2009). Influence of Strategic Planning on Performance of Public Secondary Schools in Kisumu East. (Unpublished MBA Project). University of Nairobi: Nairobi, Kenya.

- Hsieh, H-F. and Shannon, S.E. (2005). Three approaches to qualitative content analysis. In Qualitative Health Research, 15(9), (pp.1277 - 1288) 15(9), DOI: 10.1177/1049732305276687

- Johnson, S. \& Whittington, (2008). Exploring Corporate Strategy.6th Ed. New Delhi: Text and Cas-s Pearson Education ltd.

- $\quad$ Kathuri, N. \& Pals, D. (2003). Introduction to Educational Research. Njoro: Egerton University.

- Malhotra, N. K., \& Dash, S. (Ed.). (2011). Marketing research: an applied orientation. New Delhi: Pearson Pub.

- Muthoko, A. A. (2010). The influence of strategic planning on performance of public universities in Kenya: the case of university of Nairobi. Unpublished master's thesis. University of Nairobi.

- Okwako, A. D. (2013). Strategic planning and performance of public secondary schools in rarieda district, Kenya. Masters in business administration, University of Nairobi.

- Porter, M. E. (1985). Competitive Advantage: Creating and Sustaining Superior Performance. Free Press: New York.

- $\quad$ Potter, W. J. \& Levine-Donnerstein, D. (1999). Rethinking validity and reliability in content analysis. Journal of Applied Communication Research, 27(3), 258 - 284.

- Thompson, J., Strickland, A. \& Gamble, J.E. (2007). Crafting and Executing Strategy: Texts and Readings. New York: The McGraw-Hill

- Yabs, J. (2007). Strategic Management Practices in Kenya. 1st ed. Nairobi: Lelax Global ltd, 